\title{
AN INTERVAL TYPE-2 FUZZY LOGIC- BASED FRAMEWORK FOR CALL ADMISSION CONTROL IN 4G MOBILE NETWORKS
}

\author{
Uduak Umoh ${ }^{1}$, Daniel Asuquo ${ }^{2}$ and Imoh Eyoh ${ }^{3}$ \\ ${ }^{1,2}$ Department of Computer Science, University of Uyo, \\ Akwa Ibom State, Nigeria \\ ${ }^{3}$ ASAP Research Group, University of Nottingham Nottingham, \\ United Kingdom
}

\begin{abstract}
This paper presents a technique to control based on interval type-2 fuzzy logic system (IT2FLS) of Mamdani fuzzy inference, employed to model connection admission control in Fourth Generation (4G) Networks in order to improve quality of service (QoS). The appropriate parameter selection to achieve connection admission control is also considered based on major system parameters like latency, packet loss, load, signal strength and user mobility. We explore the use of Karnik-Mendel (KM) and Wu-Mendel (WM) approaches in our proposed system. We also implement a T1FLS connection admission control for guaranteed QoS in $4 G$ mobile networks for comparison purposes. The empirical comparison is made on the designed system using $4 G$ network admission control synthetic datasets. Analysis of our results reveal that the presence of additional degrees of freedom in IT2FLS-WM controller tend to reduce the root mean square error (RMSE) of the model compared to IT2FLS-KM and fuzzy type-1 approaches.
\end{abstract}

\section{KEYWORDS}

Interval type-2 fuzzy logic; Admission control system; $4 G$ Mobile Networks; Computational complexity

\section{INTRODUCTION}

Due to emerging needs for multimedia applications, a variety of access technologies such as third generation $(3 \mathrm{G})$, beyond $3 \mathrm{G}(\mathrm{B} 3 \mathrm{G})$, and $4 \mathrm{G}$ networks are developed and deployed to complement $2 \mathrm{G}$ networks and satisfy demands for mobile services and internet access. $4 \mathrm{G}$ communication networks strive to seamlessly integrate various existing wireless communication technologies with the goal of replacing the entire core of cellular networks with a single worldwide cellular network. It provides capabilities defined by International Telecommunication Union (ITU) in Internet Mobile Telephony (IMT) Advanced [1]. 4G network is believed to be the fastest network technology following the path set and commercially deployed by its wireless siblings, evolved to offer a mobile environment with high data rate up to $450 \mathrm{Mbps}$ and efficient quality of service (QoS) for real-time applications [2]. 
The increasing demand for mobile multimedia applications along with the increasing population of advance mobile devices seeking best connections anywhere and anytime comes with the challenge of providing efficient mechanisms for seamless handover among heterogeneous networks to meet specific QoS requirements. Consequently, choosing the best network to accept a new connection request without disrupting the service quality of ongoing connections becomes difficult [3] [4] [5]. Furthermore, as 4G networks are associated with much uncertainty and imprecision due to escalating number of access points, constant change in propagation channels, network load sudden variations and random mobility of users [6] [7], there is need to develop a framework that ensures fair admission control and efficient service delivery to all categories of call requests.

A Connection Admission Control (CAC) is an important decision making technique aimed at providing required QoS by restricting access to the network resources [8]. According to [3] and [9], maintaining QoS (e.g. signal quality, packet delay, jitter, loss rate, call blocking and dropping thresholds, etc.) is necessary for efficient admission control in mobile multimedia networks. Based on network load conditions for a requested connection type, the admission controller can decide to either accept or block the new request depending on the available network resources to meet the QoS requirements for the new connection without violating the QoS of already accepted requests, otherwise it is rejected. Several methods have been used to improve QoS across $4 \mathrm{G}$ networks. These methods include Markov models, queuing models, and expert systems, etc. In recent years, conventional fuzzy logic otherwise called type-1 fuzzy logic systems, arewidely used to improve the capability of existing CAC methods in mobile networks. This is due to its ability to process information using linguistic variables and making decision with imprecise, vague, ambiguous, uncertain data [12] [13].

Type-1 fuzzy logic systems (T1FLSs) have achieved great success in many different real world applications including wireless sensor networks, ATM networks, wireless cellular networks, congestion control[14] [15] [16] [17] [18] [19] [20] [21]. Despite the popularity of T1FLS, research has shown that there are difficulties in the ability of T1FLSs to model and minimize the effect of uncertainties because they provide a hard decision boundary [22] [23]. To solve this problem, type-2 fuzzy logic controllers are introduced. Type-2 fuzzy systems [24] are extensions of type- 1 fuzzy systems, characterized by membership functions that are themselves fuzzy with soft decision boundaries. T2FLSs provide additional design degrees of freedom, which can be very useful when such systems are used in situations where lots of uncertainties are present. Both the T1FLS and T2FLS consist of the same four components, which are: a fuzzification unit, a rule base, a fuzzy inference engine, and a defuzzification unit. In addition, T2FLs possess typereducer which converts T1FS output into crisp value. Recently, type-2 FLSs have been applied as a useful technique to handle all forms of uncertainties both in classification, prediction and control and the results have been promising and very encouraging [25] [26] [27] [28] [29] [30] [31] [32].

Despite the advantages offered by T2FLSs, there is the problem of computational complexity due to type-reduction computation, especially when there are many MFs and the rule base is large. To reduce the computational burden while preserving the advantages of IT2FLCs, a special case of type-2 fuzzy system called the interval type-2 fuzzy system is used [33]. IT2FLSs are widely applied in various areas because of their abilities to simplify T2FLCs [34] [35] [36]. Typically, an IT2FLS comprises five components namely, a fuzzification unit, a rule base, a fuzzy inference engine, type-reduction and defuzzificztion units. An iterative Karnik-Mendel (KM) algorithm is explored to perform type-reduction process. An extended version of type-1 defuzzification operation technique is applied on T2FSs case of the IT2FLS to obtain a T1FS at the output. The $\mathrm{T} 1 \mathrm{~F}$ set so obtained is a type-reduced set which is a collection of the outputs of all of the embedded T1-FLSs [25]. However, Karnik-Mendel (KM) algorithm is computationally complex, time-consuming with computational overhead which can reduce the real-time performance of the 
IT2-FLS and also limit their application in industrial embedded controllers. To overcome the limitations of IT2FLS in order to speed up a T2FLC, Wu and Mendel uncertainty bounds (UB) technique is employed to approximate the type-reduced set instead of using KM algorithm [37][23]. This approach is believed to reduce the computation cost of the type-reduction and the memory required for the IT2FLS implementation.

In this paper, an IT2FL connection admission control framework for guaranteed QoS in 4G network is proposed. The admission decisions are made based on system parameters like latency, packet loss, load, signal strength, and user mobility. The study employs two approaches; K-M algorithm to obtain the type-reduced sets, and Wu-Mendel uncertainty bound approach for approximation of type-reduced set to estimate the uncertainty and crisp output of an IT2FLC. Experimental results indicate that approximation of the type-reduced set using Wu-Mendel method can eliminate type-reduction computational complexity. Also, computations associated with interval type-2 fuzzy systems provide a more accurate result than T1FLS, with practical results in connection admission control in $4 \mathrm{G}$ networks. The results further indicate that, our system is able to maximize the network resource utilization by reserving resources only when needed and within the expected residence time interval. In addition, the system ensures that QoS is maintained by deciding whether a connection should be accepted or rejected thereby improving customer's quality of experience and loyalty.

\section{AN OVERVIEW OF INTERVAL TYPE-2 FUZZY LOGIC}

\subsection{Interval Type-2 Fuzzy Sets}

According to standard background material about interval type-2 fuzzy sets taken from [38], an interval type-2 fuzzy set (IT2FS), Ã is characterized as:

$$
\tilde{\mathrm{A}}=\left\{\left((\mathrm{x}, \mathrm{u}), \mu_{\tilde{\mathrm{A}}}(\mathrm{x}, \mathrm{u})\right) \mid \forall \mathrm{x} \in \mathrm{X}, \forall \mathrm{u} \in \mathrm{J}_{\mathrm{x}} \subseteq[0,1]\right\}
$$

where $x$, the primary variable, has domain $X ; u \in U$, the secondary variable, has domain $\mathrm{J}_{\mathrm{x}}$ at each $x \in X ; \mathrm{J}_{\mathrm{x}}$ is called the primary membership of $\mathrm{x}$ and the secondary grades of $\tilde{\mathrm{A}}$ all equal 1 [39]. Uncertainty about $\tilde{A}$ is conveyed by the union of all the primary memberships, which is called the footprint of uncertainty (FOU) of $A$ as shown in Fig1.

$$
\mu_{\tilde{\mathrm{A}}}(\mathrm{x}, \mathrm{u})=1, F O U(\tilde{\mathrm{A}})=\bigcup_{\forall \mathrm{x} \in \mathrm{X}} \mathrm{J}_{\mathrm{x}}=\{(\mathrm{x}, \mathrm{u}): \mathrm{u} \in \mathrm{Jx} \subseteq[0,1]\}
$$

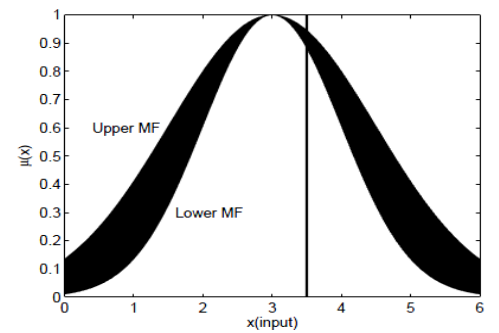

Fig 1: Interval Type-2 Fuzzy set [27]

The upper membership function (UMF) and lower membership function (LMF) of Ã are two type1 MFs that bound the FOU, i. e.

$$
\mathrm{UMF}=\bar{\mu}_{\tilde{\mathrm{A}}}(\mathrm{x}) \equiv \overline{\overline{F O U}(\tilde{\mathrm{A}})} \quad \forall x \in X
$$




$$
\begin{aligned}
\operatorname{LMF} & =\underline{\mu_{\tilde{A}}(\mathrm{x})} \equiv \underline{\operatorname{FOU}(\tilde{\mathrm{A}})} \forall x \in X \\
\mathrm{~J}_{\mathrm{x}} & =\left\{(\mathrm{x}, \mathrm{u}): \mathrm{u} \in\left[\underline{\mu}_{\tilde{\tilde{A}}}(\mathrm{x}), \bar{\mu}_{\tilde{\mathrm{A}}}(\mathrm{x})\right]\right\}
\end{aligned}
$$

where $\mathrm{J}_{\mathrm{X}}$ is an interval set. We can apply set theory operations of union, intersection and complement to easily compute for IT2 FSs

\subsection{Interval Type-2 Fuzzy Logic Systems (IT2FLS)}

Figure 2 represents an IT2FLS, which is a FLS that uses at least one IT2FS, is characterized by five components: a rule-base, a fuzzification unit, an inference-engine unit, type-reduction and defuzzification units - that are inter-connected.

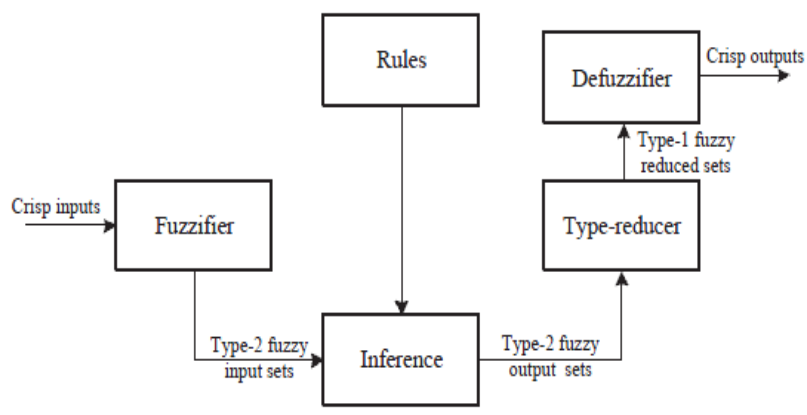

Fig. 2: Architecture of type-2 fuzzy system [27].

The type-2 fuzzy logic architecture updates a type-1 fuzzy logic system by adding the type reduction component. The IT2FLS is a mapping from crisp inputs to crisp outputs and this mapping can be expressed quantitatively as $Y=f(\mathrm{x})$. The fuzzification process maps a crisp input vector into type-1 or IT2FSs using singleton, triangular, trapezoidal or Gaussian fuzzifier. Input IT2-FSs then activate the inference engine and the rule base to produce output IT2 FSs. A typereduction unit combines the output sets and then performs a centroid calculation which produces an interval T1FS (type-reduced set). The type-reduced set is then processed by the defuzzification unit to produce crisp outputs. In type-2 fuzzy logic, rules may be provided by experts or can be extracted from numerical data which can be expressed as a collection of IF-THEN statements. An IT2FLS can be with $m$ inputs and $n$ outputs or $m$ inputs and one output. The later have the if-then rules specified as in (6).

$$
\text { IF } x_{i} \text { is } \widetilde{D}_{i}^{l} A N D, \ldots, A N D x_{m} \text { is } \widetilde{D}_{m}^{l} \text { THEN y is } \widetilde{E}^{l}
$$

Where $x_{i}, i=1, \ldots, m$ are the antecedents, $y$ is the consequent of the $l$ th rule of IT2FLS. The $\widetilde{D}^{i}$ 's are the MFs $\mu_{\widetilde{D}_{i}^{l}}\left(x_{i}\right)$ of the antecedent part assigned of the $i$ th input $x_{i}$, The $E^{l}$ is the MFs $\mu_{\tilde{E}_{j}^{l}}(y)$ of the consequent part assigned to the output $y_{j}$.

The result of the input and antecedent operations contained in the firing set produces an interval type-1 set as shown in (7) [26].

$$
F^{i}\left(x^{\prime}\right)=\left[\underline{f^{\prime}}\left(x^{\prime}\right), \overline{f^{\prime}}\left(x^{\prime}\right)\right] \equiv\left[f^{\prime}, \overline{f^{\prime}}\right]
$$

where $F^{i}\left(x^{\prime}\right)$ is the antecedent of rule $i$ and $\mu_{F 1}{ }^{i}\left(x^{\prime}\right)$ is the degree of membership of $x$ in F. $\bar{\mu}_{\tilde{f}^{i}}(\mathrm{x})$ and $\underline{\mu}_{\tilde{f}^{i}}(\mathrm{x})$ are upper and lower MFs of $\mu_{\tilde{f}^{i}}, i=1$ to $m$ respectively. 
The inference engine combines the fired rules and gives a mapping from input to output in IT2FSs. The combined output fuzzy set, $\mu_{\tilde{E}_{j}^{l}}\left(y_{j}\right)$, is obtained by combining the fired output consequent sets by taking the union of the ith rule fired output consequent sets.

\subsection{Interval Type-2 Fuzzy Logic Systems (IT2FLS}

From the standard background material on type-reduction and defuzzification in an IT2FLS taken from [38], five different Type-reduction (TR) techniques are defined, where the type-reduced set gives an interval of uncertainty for the output of an IT2FLS. The more uncertainties in an IT2FLS, the more uncertainties about its MFs, the larger the type-reduced set, and vice-versa. Although, computing the centroid of a general T2FS is complex; for an IT2FS, an exact iterative method of type-reduction is performed to compute the centroid of an IT2FS which is a T1FS. IT2FS are characterized by their left- and right-end points required to compute the centroid of an IT2FS [23][40][25].

Center-of-sets, centroid, center-of-sums, and height type-reduction can all be expressed in [27][29] as

$$
\begin{aligned}
& Y_{T R}\left(x^{\prime}\right)=\left[y_{l}\left(x^{\prime}\right), y_{r}\left(x^{\prime}\right)\right] \equiv\left[y_{l}, y_{r}\right]=\int_{y^{1} \in\left[y_{l}^{1}, y_{r}^{1}\right]} \cdots \int_{y^{1} \in\left[y_{l}^{N}, y_{r}^{N}\right]} \int_{f^{1} \in\left[f^{1}, \bar{f}^{1}\right]^{\prime}} \cdot \int_{f^{N} \in\left[\underline{f}^{N}, \bar{f}^{N}\right]} 1 / \\
& \frac{\sum_{i=1}^{N} f^{i} y^{i}}{\sum_{i=1}^{N} f^{i}}
\end{aligned}
$$

TR center-of-sets (COS) are mostly used where $y_{l}^{i}$ and $y_{r}^{i}$ are the left and right end points of the centroid of the consequent of the $i$ th rule while $f^{i}$ and $\bar{f}^{i}$ are the lower and upper firing degrees of the $i$ th rule and $N$ is the number of fired rules.

KM Algorithms in [41] are employed for computing the end-points exactly and are presented in (9) and (10) respectively;

$$
\begin{gathered}
y_{r}=\frac{\sum_{i=1}^{N} f_{r}^{i} y_{r}^{i}}{\sum_{i=1}^{N} f_{r}^{i}} \\
y_{l}=\frac{\sum_{i=1}^{N} f_{l}^{i} y_{l}^{i}}{\sum_{i=1}^{N} f_{l}^{i}}
\end{gathered}
$$

Defuzzification of the interval set is performed using the average of $y_{l k}$ and $\mathrm{y}_{\mathrm{rk}}$, and the defuzzified crisp output for each output $k$ is achieved;

$$
Y_{k}(X)=\frac{y_{l k}+y_{r k}}{2}
$$

\subsection{An IT2FLS Using Wu-Mendel Uncertainty Bounds}

The Type-reduction is computationally intensive, time-consuming and associated with output uncertainty for a real-time application of an IT2FLS. However, to overcome the limitations of IT2FLS in order to speed up a T2FLC, Wu-Mendel uncertainty bounds technique is employed to approximate the type-reduced set. The inner- and outer-bound sets (called minimax uncertainty bounds) are provided for the type-reduced set to estimate the output uncertainty of IT2FLS and directly perform defuzzification to obtain output under certain conditions [23] [37]. 
These uncertainty bounds are $\underline{y}_{l}\left(x^{\prime}\right), \bar{y}_{l}\left(x^{\prime}\right), \underline{y}_{r}\left(x^{\prime}\right), \bar{y}_{r}\left(x^{\prime}\right)$ as expressed in details in [37], where $\underline{y}_{l}\left(x^{\prime}\right) \leq y_{l}\left(x^{\prime}\right) \leq \bar{y}_{l}\left(x^{\prime}\right)$ and $\underline{y}_{r}\left(x^{\prime}\right) \leq y_{r}\left(x^{\prime}\right) \leq \bar{y}_{r}\left(x^{\prime}\right)$

The type-reduction sets are approximated without having to perform TR and also defuzzify directly to obtain the output in (12) and (13) [37] as follows:

$$
\left.\left[y_{l}(x), y_{r}(x)\right] \approx\left[\underline{\left(y_{l}\right.}(x)+\bar{y}_{l}(x)\right) / 2,\left(\underline{y_{r}}(x)+\bar{y}_{r}(x)\right) / 2\right]
$$

The output of IT2FLS is given as;

$$
y(x)=\frac{1}{2}\left[y_{l}(x), y_{r}(x)\right]=\frac{1}{2}\left[\left(y_{l}(x)+\bar{y}_{l}(x)\right) / 2+\left(\underline{y}_{r}(x)+\bar{y}_{r}(x)\right) / 2\right]
$$

\section{PROPOSED INTERVAL TYPE-2 FUZZY LOGIC FRAMEWORK FOR CALL ADMISSION CONTROL IN 4G NETWORKS}

The In this paper, a $4 \mathrm{G}$ connection admission control framework is proposed using interval type- 2 fuzzy logic technique in order to improve QoS. The choice of this technique lies in its ability to handle uncertainty associated with variables used in connection admission decision more effectively compared to type-1 fuzzy logic model. Connection admission factor (CAF) is determined for effective decision on call admission into the network and for proper management of network's resources based on the impact of these indictors (variables) - latency, packet loss, load, signal strength, and user mobility. The general structure of an IT2FLS for CAC in 4G networks is presented in Figure 3. The Model of the Proposed IT2FL-AC is shown in Figure 4.

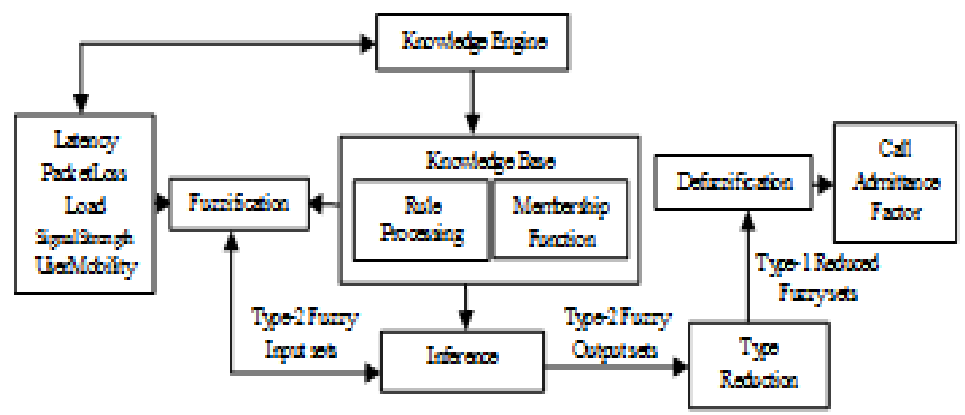

Fig. 3: Type-2 Fuzzy logic model for call admission control

In Figure 3, there are five inputs latency (LA), Packet Loss (PL), Signal Strength (SS), Load (LD), and User Mobility $(U M)$ obtained from the knowledge engine and one output, Call Admittance Factor $(C A F)$ for determining the degree of acceptability or otherwise of call request. General T2FLSs are computationally complex [42]. However, T2FLC is simplified using IT2FLS. In this paper, IT2FLS as discussed is employed for controlling call admission parameters.

In layer one, fuzzy linguistic variables (input parameters) are defined as $L A, P L, S S, L D$, and $U M$. The linguistic terms for each of $L A, P L$, and $U M$ are Low (L), Medium $(\mathrm{M})$, and High $(\mathrm{H}) . L D$ has Very Low (VL), Low (L), High (H) and Very High (VH) as linguistic terms while Weak (W), Moderate (M), and Strong (S) are the linguistic terms for SS. Their MF plots in MATLAB are as shown in figures $9(\mathrm{a})-(\mathrm{e})$. The output parameter - CAF is described using four linguistic terms which are Poor (P), Fair $(F)$, Good (G,) and Excellent $(E)$, as shown in Figure 4. The MF limits are selected based on input parameters and applied for reducing footprint of uncertainties. The MFs of these fuzzy sets contain five inputs and one output. These inputs are converted and 
fuzzified into input interval type-2 fuzzy sets, and then are mapped to the linguistic labels of fuzzy sets to determine their degree of membership.

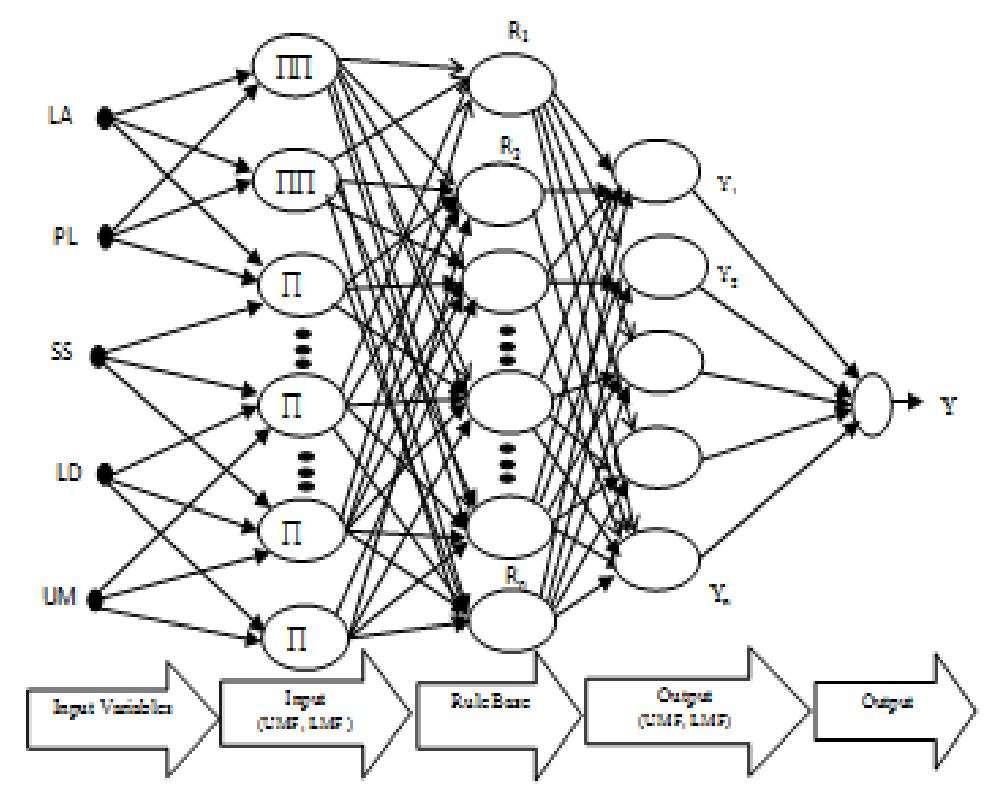

Fig. 4: The Model of the Proposed IT2FLCAC- adapted from [43]

This work considers IT2 Gaussian MFs with uncertain width (deviation) because it is suitable for highly dynamic random networks such as $4 \mathrm{G}$.

$$
f(x)=e^{\frac{-1}{2}\left(\frac{x-c}{\sigma}\right)^{2}}, \sigma \in\left[\sigma_{1}, \sigma_{2}\right] \text { and } c \in\left[c_{1}, c_{2}\right]
$$

That is $\sigma \in\left[\sigma_{1}, \sigma_{2}\right]$ with upper and lower membership functions defined as follows:

$$
\begin{aligned}
& \bar{\mu}_{\tilde{\AA}_{i m}}\left(x_{i}\right)=\exp \left(-\frac{x_{i}-c_{i m}}{2 \bar{\sigma}_{2, i m}^{2}}\right), \bar{\mu}_{\tilde{\AA}}(x)=N\left(c, \sigma_{2} ; x\right) \\
& \underline{\mu}_{\tilde{\AA}_{i m}}\left(x_{i}\right)=\exp \left(-\frac{x_{i}-c_{i m}}{2{\underline{\sigma_{1}}}_{1, i m}^{2}}\right), \underline{\mu}_{\tilde{A}}(x)=N\left(c, \sigma_{1} ; x\right)
\end{aligned}
$$

Where $\mathrm{c}$ is the center (mean) of the MF, $\sigma$ is the width (standard deviation) of the MF and $x$ is the input vector. The variables $\bar{\sigma}_{2, i m}$ and $\underline{\sigma}_{1, i m}$ are premise parameters that define the degree of membership of each element to the fuzzy set $\tilde{A}$ and FOUs of the IT2IFS. The detail description is found in [33] [23]. MFs are defined and evaluated for all the input and output linguistic variables. IT2F sets are explored in the antecedents' parts and each MF of the antecedent part is represented using an upper and a lower MFs, denoted by $\bar{\mu}_{\tilde{\mathrm{A}}}(\mathrm{x})$ and $\underline{\mu_{\tilde{A}}}(\mathrm{x})$ as described in [33]. Each node output indicates the lower and upper interval.

In layer two, the fuzzy rules are defined based on (6). One example is expressed as: IF Latency is High and Packet Loss is Moderate and Load is High and Signal Strength is Strong and User Mobility is Low THEN CAF is FAIR = [0.32, 0.29]. 243 rules were defined in the rule base for the IT2 FLC based on human expert opinion. For simplicity, parts of the rules are presented in Table 1. In the IT2FLS, the rule base part are enclosed with five antecedents $(L A, P L, S S, L D, U M)$ which divide the input space into a set of fuzzy regions and one consequent (CAF) part which 
describes the system behavior in those regions. Each MF of the antecedent part is represented by an upper and a lower membership function

In layer three, the inference engine combines fired rules, maps input IT2 fuzzy sets and output IT2 fuzzy sets by computing unions and intersections of type- 2 sets, as well as compositions of type-2 relations. The main problem is to determine the effect of input parameters in the antecedent part such that a concise representation of the system's behavior is produced in the consequent part, i.e. network connection admission. This paper uses Mamdani fuzzy inference engine to calculate the firing strengths of the $i$ th rule illustrated in (7).

Layer Four: In this layer, type reducer maps IT2FS into a T1FS by combining the fuzzy output sets (IT1FS). In our paper, IT2FLC-AC employs center-of-sets type-reduction [44], and applies the iterative Karnik-Mendel (KM) procedures illustrated in section 4 of this paper, to calculate correct values of type-reduced sets. IT1FS is determined by its two end points, $y_{1}$ and $y_{r}$ in (9) and (10).

Layer five: Defuzzification is performed in this layer by mapping the T1FS into a crisp number by computing the interval output of this layer for each node present in this layer respectively. The final output of T2FLS-AC, which is a numeric value, is obtained by averaging the output of the resultant effect of the four embedded T1FLS using (10).

However, it is observed that K-M type-reduction scheme shows a major bottleneck using an interval type-2 FLS in real-time practices. We employ Wu-Mendel uncertainty bounds approximation method illustrated in section 5 of this work, to estimate the type-reduced sets and then determine the output of the FLS directly in to eliminate type-reduction.

Next, we present our model experiment and discussion of simulation results. We use the root mean square error (RMSE) performance criterion for our experiments which is defined as:

$$
R M S E=\sqrt{\frac{1}{N} \sum_{i=1}^{N}\left(y^{x}-y\right)^{2}}
$$

Where $y^{x}$ is the desired output, $\mathrm{y}$ is our model output and $\mathrm{N}$ is the number of data items.

\section{MODEL EXPERIMENT RESULTS}

In this paper, IT2FL controller using KM type-reduction method and the IT2FL controller using the Wu-Mendel UB method are applied to a non-linear system control problem in $4 \mathrm{G}$ mobile networks where 200 datasets are generated based on the variables; latency, Packet Loss, Signal Strength, Load, and User Mobility which are used as inputs and call admittance factor is the desired output. For each input in this study, Gaussian membership functions with fixed mean and uncertain standard deviation are used. An IT2FLS-AC and T1FLS-AC are implemented for comparison purposes. Fuzzy logic toolbox in Matlab 7.5.0 is used for the input and output membership functions plots as presented in Figures 5(a)-(f) respectively. The results of applying different approaches to the admission control in $4 \mathrm{G}$ networks to guarantee efficient QoS are shown in Table1 and graphs are presented in Figures (6) to (8) respectively. The result of RMSE performance criterion for our experiment is presented in Table 2. 


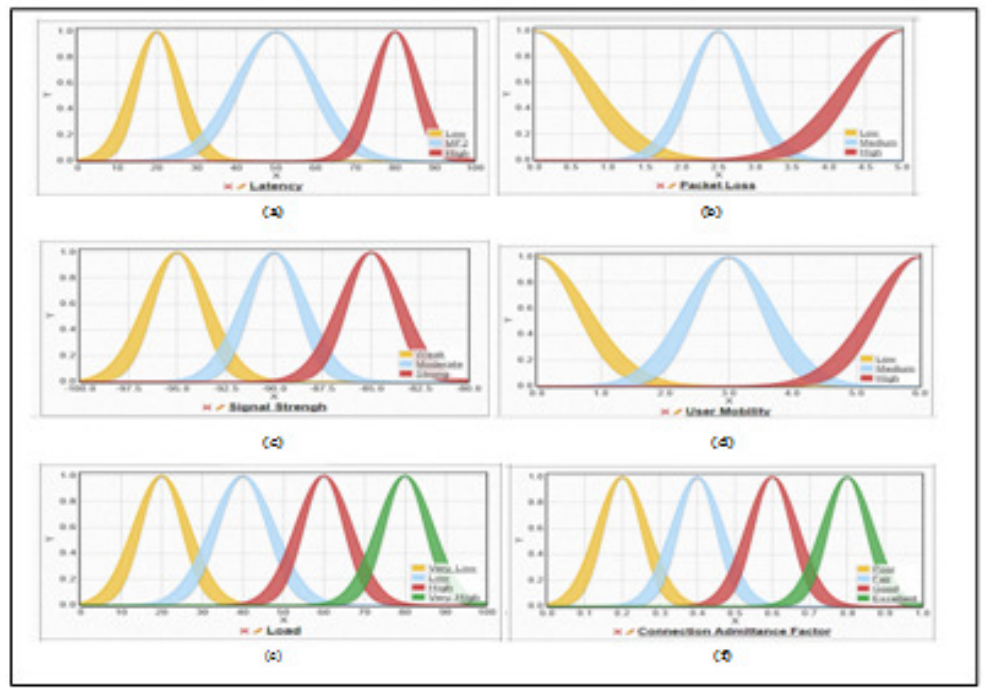

Fig. 5: (a) Latency (b) Packet Loss (c) Load (d) Signal Strength (e) User Mobility (input IT2 Membership Functions for) and (f) Output membership functions (CAF)

Table 1: Experimental Results

\begin{tabular}{|c|c|c|c|c|c|c|c|c|c|c|}
\hline \multicolumn{11}{|c|}{ IT2FL and IT1FL Call Admission Results } \\
\hline \multirow[b]{2}{*}{$S / N$} & \multirow[b]{2}{*}{ Whengy } & \multirow[b]{2}{*}{ Padket tons } & \multirow[b]{2}{*}{ Loud } & \multirow[b]{2}{*}{ Sipnal Strength } & \multirow[b]{2}{*}{ Uner Motility } & \multirow[b]{2}{*}{$n$} & \multirow[b]{2}{*}{$\mathrm{rr}$} & \multicolumn{2}{|c|}{$\pi 2 f$} & \multirow{2}{*}{$\frac{T 1 F L}{\pi D L}$} \\
\hline & & & & & & & & $\mathrm{km}$ & wu & \\
\hline & 23.39761925 & $4 \pi 0491591$ & 34.10509963 & 858191631 & 4.16059574 & 0.5s1725187 & a.cosocsens & 0.530358794 & $0.630167 \pi 8$ & 0.52 \\
\hline & 59.1317200 & 4835350035 & 29.9935016 & -9316553393 & 2212117672 & Q.mmsan & 0.592386586 & 0.90612272 & 0.96431758 & 0.55 \\
\hline & $2.0055506 \pi$ & 4.9574atse & 40.05202059 & s. & 105722824 & 0.45ezusus9 & a.ssoesion: & $0.8002 \times 45$ & 0.6000005s & QS \\
\hline 4 & $28.5825 \mathrm{~mm}$ & 1.556679049 & 0.518451334 & .9871507263 & 257207345 & 0.354729547 & 0.7878585004 & 0.301309625 & 0.8013212 & 0.75 \\
\hline 5 & 57.64119049 & 1.7usubes & 3..152855 & 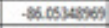 & $1.4190 \times 024$ & & 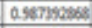 & Q.Mvescast & Q.mo12sese & 0.7 \\
\hline 6 & 36.43525239 & 0.46735653 & 3423316956 & $-92.6 \pi 00039$ & 3.362528591 & 0.9999993634 & 0.859302781 & e.9e9n7nss & a.s4scricoss. & 0.75 \\
\hline 7 & 25.43228531 & 1.T70384508 & 4.708764939 & 91.43655913 & 0.983432551 & 0.978362567 & 0.206030975 & 0593196821 & 0.617159658 & 0.43 \\
\hline 8 & 92.47552074 & 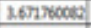 & 7.30045 & - sesmencs & $0.5405 \sin 202$ & 0.62434072 & $0.01 \times 1 \times 072$ & $0.72315=92$ & 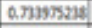 & 0.7 \\
\hline 9 & 29.7520638 & $0.5 \pi 9152 \pi$ & 99.39520556 & .9620104797 & 5.459224434 & & 0.859604023 & Q.94581231 & $0.545612 \mathrm{mi}$ & 0.7 \\
\hline 10 & $37.39 \mathrm{mBs}$ & 4.14055735s & 45.0000509? & 97.59897638 & 4.743130275 & $0.9 m 246516$ & 0.393585850 & 0.656553724 & 0.700956027 & 0.55 \\
\hline 11 & 73.30000456. & $0.5 \pi 0180$ se & 13.20002258 & 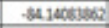 & 1.500031213 & 0.30945652 & $0.25 \operatorname{scos} 00 \mathrm{st}$ & 0.2970920060 & a.25197sese & 0.09 \\
\hline 12. & 9050450825 & 1.187733412 & 48.90061722 & 81.58362579 & $3.8519067 \mathrm{mb}$ & 0.55996445 & . 0.6507075 & 0.052520786 & 0.558533482 & 0.8 \\
\hline 13. & 25.13:345456 & Q. 36010125 & 55 Sectunat & $-91.56 \operatorname{sect} 1$ & $2 \times 67356256$ & 0.56127206 & 0.200000576 & 0.55073822 & 0.5722073 & 0.5 \\
\hline 14 & 25.30006013 & 2961541358 & 35.22211446 & $98 \pi 5013116$ & $3002115 s=7$ & 0.06790626 & 0.006371360 & 6.63813958 & acsessecoch & 2.5 \\
\hline 13 & 36.0912345 & 4166234005 & 85.61044312 & .989307562 & $5.994147 m$ & $0.939 m 6951$ & 0.856933896 & 0.594456738 & 0.545511154 & 0.72 \\
\hline 16 & 44.motess4 & 4SON119e & 66.5010365 & $-\operatorname{ses} 516010$ & 4.62345126 & \begin{tabular}{|l|l|} 
Q.m239: \\
\end{tabular} & a.mosionow & Q.mstses & o.9m39s & 0.75 \\
\hline 17 & $57.173134 \pi$ & 4.864745617 & 57.4064798 & 88.15919496 & 0.09990006 & 0.999997491 & 0.997864367 & 0.999930929 & 0.99501652 & 0.74 \\
\hline 13 & 48.1325798 & $2866 \pi \times 0536$ & 92.74352254 & -84.471527 & 1.42535S419 & 0.9m39181 & $0.201135 \times 66$ & 0.600537473 & 0.603456562 & 0.65 \\
\hline 19 & 2.453929961 & 2.22074ss & 57.91403452 & 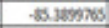 & 4550435066 & 0.650325344 & 0.00000001 & $0.0253 \times 5592$ & 0.02535592 & 0.43 \\
\hline 20 & 93.65456597 & 443977978 & 47.34951732 & .98 .0142365 & 1339944701 & 0.650046116 & 0.79265324 & 0.701349679 & a.JOSS4719 & os \\
\hline 21 & 12.matsses & 2.921215546 & $n 5200030$ & $\$ 6.651076$ & $0.5 \sin 4224$ & 0.9.352rs & a.sstsoness & 0.962 te6633 & 0.54337595s & 0.72 \\
\hline & ot movoten & formentas & $x \operatorname{sinnon}$ & & & & & & & $a$ \\
\hline
\end{tabular}

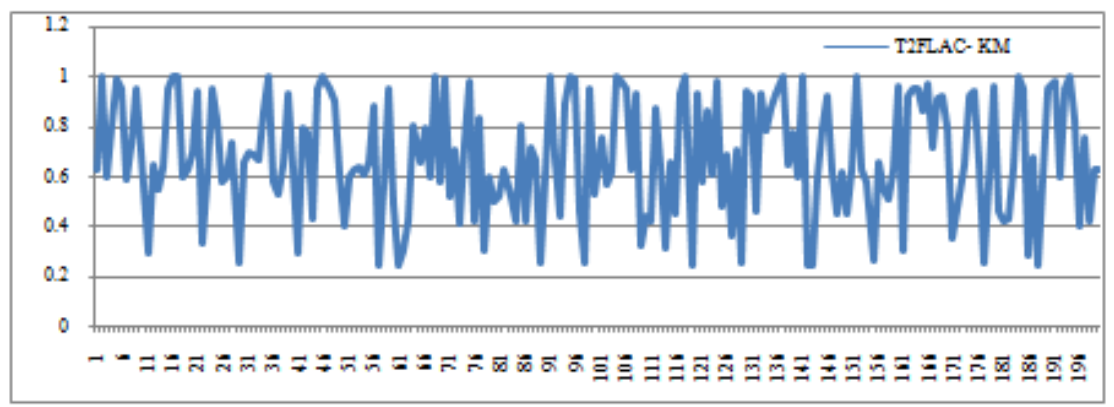

Fig. 6: Graph of the result of Interval Type-2 Fuzzy Logic Admission Control using KM approach 


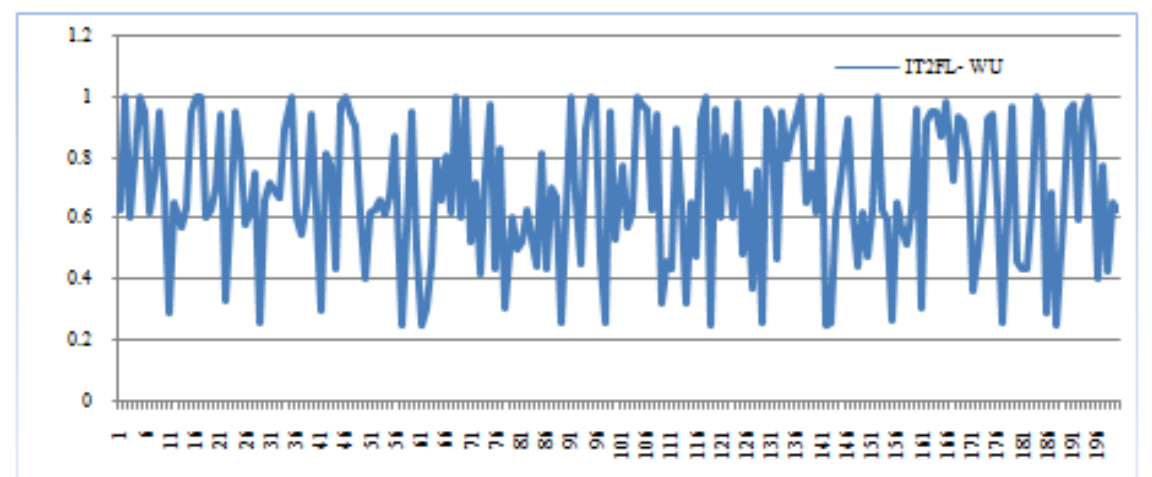

Fig. 7: Graph of the result of Interval Type-2 Fuzzy Logic Admission Control using WU approach

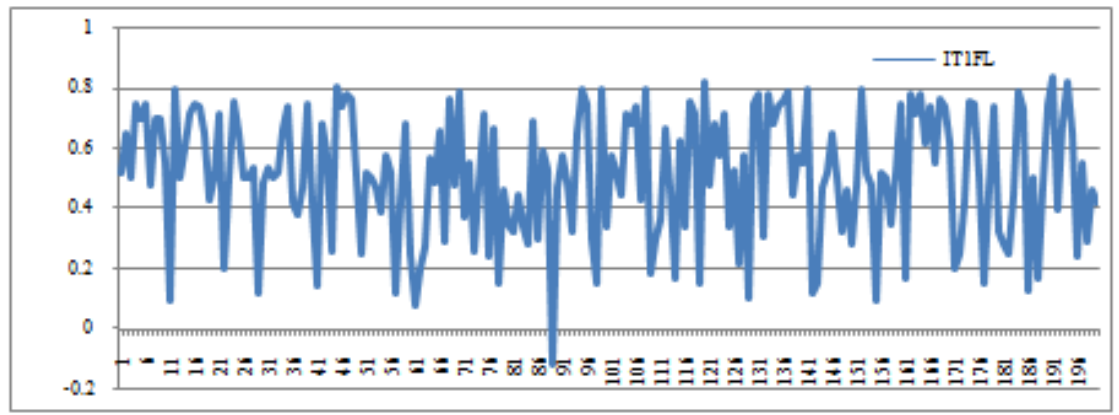

Fig. 8: Graph of the result of Interval Type-1 Fuzzy Logic Admission Control

Table 2: Comparison of IT2FLS-KM, IT2FLS-UM and ITIFLS in Admission Control in 4G Networks

\begin{tabular}{|l|l|l|l|l|}
\hline Models & $\begin{array}{l}\text { Training/C } \\
\text { hk }\end{array}$ & Mean & $\begin{array}{l}\text { Standard } \\
\text { Deviation }\end{array}$ & $\begin{array}{l}\text { Root Mean Square } \\
\text { Error (RMSE) }\end{array}$ \\
\hline IT1FLAC & $400 / 200$ & 0.5123 & 58.6776 & 0.0456 \\
\hline $\begin{array}{l}\text { IT2FLAC- } \\
\text { KM }\end{array}$ & $400 / 200$ & 0.6789 & 51.5483 & 0.0021 \\
\hline $\begin{array}{l}\text { IT2FLAC- } \\
\text { WM }\end{array}$ & $400 / 200$ & 0.6876 & 48.2197 & 0.0016 \\
\hline
\end{tabular}

The results of applying different approaches to the connection admission control problem are as listed in Table 1 and in Figures (6) to (8) indicate that generally, IT2FLS using Wu-Mendel method outperforms Karnik-Mendel on the same set of input parameters. For example, with 35\% low latency, $1 \%$ low packet loss, 56\% low load, -91.9 signal strength and 2\% moderate user mobility, $57 \%$ good CAF is achieved using WU approach as against 55\% good CAF with $\mathrm{Km}$ method. However, it is also observed that approximately $100 \%$ optimal value in terms of QoS demands and overall network performance is achieved using both approaches with $44 \%$ medium latency, 5\% high packet loss, 67\% high load, $-85 \%$ strong signal strength and 5\% high user mobility. RMSE performance measure applied in the work, as shown in Table 2 after training. IT2FLS using WM give 0.0016 RMSE, outperforms IT2FLS using KM with 0.0021 RMSE, because the lower the error, the better the performance of the technique. We also implement a T1FLS for connection admission control in $4 \mathrm{G}$ Networks in order to comparatively evaluate the performance of the IT2FLS-AC with the T1FL model, where results indicate that IT2FLS-AC outperforms T1FLS because of the extra degrees of freedom offered by the FOUs of the IT2FLSs. The overall result shows a $1.62 \%$ improvement of IT2FLS with WM over IT2FLS KM and 
$87.07 \%$ over T1FLS. This indicates that there is a significant performance improvement of IT2FLS over T1FLS on system control.

\section{CONCLUSION}

In this study, an IT2FLS approach to control is presented. The IT2FLS can accommodate more imprecision thereby modelling imperfect and imprecise knowledge better than some T1FLS. The main problem is to determine the effect of input parameters in the antecedent part such that a concise representation of the systems behavior is produced in the consequent part, i.e. network connection admission. The key point in this design is the use of IT2FL to model the level of uncertainty of every element in each set. In future, we intend to learn the parameters of the IT2FLS using Gaussian membership function with uncertain mean and also to train IT2FLS using hybrid approach of neural networks and particle swarm optimization and to apply on network connection admission control datasets for more effective guarantee of QoS.

\section{REFERENCES}

[1] M. E. Dien, A. A. Youssif, A. Z. Ghalwash "Energy Efficient and QoS Aware Framework for Video Transmission over Wireless Sensor Networks". Wireless Sensor Network, 2016, vol. 8, pp 25-36.

[2] R. Sepúlveda, O. Ross, J. Quĩnones-Rivera, and E. Quiroz "WLAN Cell Handoff Latency Abatement Using an FPGA Fuzzy Logic Algorithm Implementation. Hindawi Publishing Corporation Advances in Fuzzy Systems. Vol, 2012, Article ID 219602, 1-10 s doi:10.1155/2012/219602

[3] S. Kumar, K. Kumar and K. Pandey "A Comparative Study of Call Admission Control in Mobile Multimedia Networks using Soft Computing. International Journal of Computer Applications (0975 8887) Vol. 107 Issue 16, pp 1-7, 2014.

[4] P. Metre, K. Radhika, Gowrishankar "Survey of Soft Computing Techniques for Joint Radio Resource Management", 978-1-4673-1520, IEEE 2012.

[5] P. Payaswini, D.H. Manjaiah "Challenges and issues in 4G - Networks Mobility Management". International Journal of Computer Trends and Technology (IJCTT) - volume4 Issue5-May 2013, 1247-1251, 2013.

[6] A. A. Atayero and M. K. Luka "Applications of Soft Computing in Mobile and Wireless Communications". International Journal of Computer Applications (0975 - 8887), vol. 45 No. 22, pp 48-55, 2012.

[7] I. F. Akyildiz, D. M. Gutierrez-Estevez, E. C. Reyes "The evolution to 4G cellular systems". LTE Advanced Physical Communication, vol. 3 pp 217-244, 2010.

[8] A. Shukla, Super-Fast 4G Wireless Service Launching in South Korea. Asia-Pacific Buisness and Technology Report, 2011.

[9] G. Mahesh, S. Yeshwanth, U. V. Manikantan "Survey on Soft Computing based Call Admission Control in Wireless Networks". International Journal of Computer Science and Information Technologies, Vol. 5 No. 3, pp 3176 - 3180, 2014.

[10] A. M. Miyim, M. Ismail, R. Nordin and M. T. Ismail "Regressive Prediction Approach to Vertical Handover in Fourth Generation Wireless Networks". J. ICT Res. Appl., vol. 8, No. 1, pp 31-48, 2014.

[11] L. A. Zadeh "Fuzzy Sets". Information and Control, vol. 8, pp 338-353, 1965. 
[12] O. Castillo, P. Melin "Type-2fuzzylogic: theory and application”. Studfuzz, vol. 223, pp. 29-43, 2008.

[13] E. H. Mamdani and S. Assilian "An experiment in linguistic synthesis with a fuzzy logic controller". International Journal of Man-Machine Studies, vol. 7, no.1, pp. 1-13, 1975.

[14] M. V. Ramkumar, A. D. Mihovska, N. R. Prasad and R. Prasad "Fuzzy-Logic Based Call Admission Control for A Heterogeneous Radio Environment". International Jornal of Research in Computer Science, vol. 3, Issue 4, 2016.

[15] M. P. Selvi and S. Sendhilnathan "Fuzzy Based Mobility Management in 4G Wireless Networks". Brazilian Archives of Biology and Technology. vol. 59 no. spe2, 2016, http://dx.doi.org/10.1590/1678-4324-2016161047.

[16] G. U. Mali "Fuzzy Based Vertical Handoff Decision Controller for Future Networks". International Journal of Advanced Engineering, Management and Science (IJAEMS) vol. 3, no.1, 111-119, Jan2017.

[17] R. Abbasi, A. Bidgoli and M. Abbasi, “A New Fuzzy Algorithm For Improving Quality of Service In Real Time Wireless Sensor Networks". International Journal Of Advanced Smart Sensor Network Systems ( IJASSN ), vol. 2, no. 2, pp 1-14, 2012.

[18] A. Dogman, R. Saatchi, and S. Al-Khayatt, "Quality of Service Evaluation using a Combination of Fuzzy C-Means and Regression Model”. World Academy of Science, Engineering and Technology vol. 6, pp. 562-571, 2012.

[19] J. Ye, X. Shen, and J. Mark, "Call admission control in wideband CDMA cellular networks by using fuzzy logic”. IEEE Trans. Mobile Comput., vol. 4, no. 2, pp. 129-141, 2005.

[20] C. Sonmez, O. Incel, S. Isik, M. Donmez and C. Ersoy, "Fuzzy-based congestion control for wireless multimedia sensor networks". Sonmezet al. EURASIP Journal on Wireless Communications and Networking, no. 63, pp 1-17, 2014.

[21] Y. Bazaz1, S. Kumar and S. Anand, "Congestion Control Mechanism using Fuzzy Logic".International Journal of Emerging Trends \& Technology in Computer Science (IJETTCS) vol. 2, no. 2, pp. 313-319, 2013.

[22] H. Hagras “Type-2 flcs: A new generation of fuzzy controllers".IEEE Computational Intelligence Magazine, vol. 2, no. 1, 30-43, 2007.

[23] J. M. Mendel, Uncertain Rule-Based Fuzzy Logic Systems: Introduction and New Directions, Prentice-Hall, Upper Saddle River, NJ, 2001.

[24] L. A. Zadeh, "The concept of a linguistic variable and its application to approximate reasoning-1," Inf. Sci., vol. 8, pp. 199-249, 1975.

[25] N. N. Karnik and J. M. Mendel, "Centroid of a type-2 fuzzy set," Information Sciences, vol. 132, pp. 195-220, 2001.

[26] D. R.Wu and W. W. Tan "Computationally efficient type-reduction strategies for a type-2 fuzzy logic controller”, in FUZZ-IEEE, Reno, USA pp. 353-358, , May, 2005.

[27] Wu, Dongrui (2005), Design and analysis of Type-2 Fuzzy Logic Systems. A Master's Thesis, Department Of Electrical Aad Computer Engineering, National University of Singapore 2005

[28] J. M. Mendel, "Fuzzy sets for words: a new beginning," in Proceedings of the 12th IEEE International conference on Fuzzy Systems, pp. 37-42, Los Angeles, Calif, USA, May 2003. 
[29] D. Wu and J. M. Mendel, “A vector similarity measure for linguistic approximation: interval type-2 and type-1 fuzzy sets," Information Sciences, vol. 178, no. 2, pp. 381-402, 2008.

[30] H.M. Fayek , I.Elamvazuthi N.Perumal , B.Venkatesh (2014). A controller based on OptimalType-2 FuzzyLogic:Systematic design, optimization and real-time implementation. ISA Transactions, vol. 53, pp. 1583-1591, 2014.

[31] Q. Ren, M. Balazinski and Luc Baron "Type-2 TSK Fuzzy Logic System and its Type-1 Counterpart”. International Journal of Computer Applications (0975 - 8887) vol. 20. no.6, pp. 8-14, April 2011.

[32] R. Sarojinee, V. Gupta, M. K. Jha and M. F. Qureshi "Development of Interval Type-2 Fuzzy Logic Controller for Polymer Extruder Melt Temperature Control”. International Journal of Innovative Research in Science, Engineering and Technology, Vol. 4, Issue 2, February 2015, 593-605.

[33] Q Liang, N. N. Karnik "Connection Admission Control in ATM Networks Using Survey-Based Type2 Fuzzy Logic Systems'. IEE Transactions on Systems, Man, and Cybernetics-Part C: Applications and Reviews, vol. 30, no. 3., pp. 329-340, August 2000.

[34] S. Shukla, M. Jha, M. F. and Qureshi "An Interval Type-2 Fuzzy Logic Approach for Induction Motors Stator Condition Monitoring”. IJISET - International Journal of Innovative Science, Engineering \& Technology, vol. 1 no. 5, 96-112, July 2014.

[35] M. Khosla, R. K. Sarin and M. Uddin "Design of an Analog CMOS Based Interval Type-2 Fuzzy Logic Controller Chip”. International Journal of Artificial Intelligence and Expert Systems, vol. 2, no. 4, 169-186, 2011.

[36] E. A. Jammeh, M. Fleury, C. Wagner, H. Hagras, and M. Ghanbari, "Interval type-2 fuzzy logic congestion control for video streaming

[37] H. Wu and J. M. Mendel "Uncertainty Bounds and Their Use in the Design of Interval Type-2 Fuzzy Logic Systems”. IEEE Transactions on Fuzzy Systems, vol. 10, no. 5, 622-640, 2011.

[38] J. Mendel, H. Hagras and R. John Standard Background Material About Interval Type-2 Fuzzy Logic Systems. "Unpublished".

[39] J. Mendel and R. John, “Type-2 fuzzy sets made simple,” IEEE Transactions on Fuzzy Systems, vol. 10, no. 2, pp. 117-127, 2002.

[40] N. N. Karnik, J. M. Mendel and Q. Liang, “Type-2 fuzzy logic systems,” IEEE Trans on Fuzzy Systems, vol. 7, pp. 643-658, Dec. 1999.

[41] J. M. Mendel and F. Liu, "Super-exponential convergence of the Karnik-Mendel algorithms for computing the centroid of an interval type-2 fuzzy set," accepted for publication in IEEE Trans on Fuzzy Systems, 2006.

[42] Hani Hagras, (2009), “General Type-2 Fuzzy Logic Systems to Enable Better Uncertainty Handling for Real World Application”. The University of Essex, England, UK.

[43] U. A. Umoh and U. G. Inyang 'A Fuzzy-Neural Intelligent Trading Model for Stock Price Prediction”. IJCSI International Journal of Computer Science Issues, vol. 12, no. 3, pp. 36-44, May 2015.

[44] O. Castillo and P. Melin, Recent Advances in Interval Type-2 Fuzzy Systems vol. 1. USA: Springer, 2012. 


\section{AUTHORS}

Umoh U. A. had received her Doctor of Philosophy (PhD) degree in Soft Computing from University of Port Harcourt, Rivers State, Nigeria in the year 2012, Master's degree in Database Management System from University of Port Harcourt, Rivers State, Nigeria in the year 2006 and Bachelor's degree from University of Uyo, Akwa Ibom State, Nigeria in 2007. She is currently working as a Senior Lecturer, in the University of Uyo in the Department of Computer Science. She has published several articles in her areas in reputable national and international journals and has written some quality books in Computer discipline. Her area of interest include; Soft

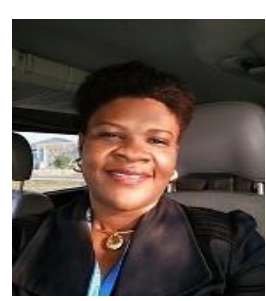
Computing (Fuzzy System, Neural network, Hybrid models), Database System, Data Communications, etc. She is a member of Nigerian Computer Society (NCS), Member, Computer Professionals Registration Council of Nigeria (CPN), member, Nigerian Women in Information Technology (NWIT), member, Organization for Women in Science in Developing World (OWSD), member, Universal Association of Computer and Electronics Engineers (UACEE), member, Soft Computing Research Group (SCRS), member, Internet Society (ISOC), etc.

Daniel Asuquo graduated from the University of Calabar, Nigeria, in 2002 with a B.Sc. degree in Computer Science. In 2007, he received a M.Sc. degree in Computer Science from the University of Ibadan, Nigeria and in 2015, he received a Ph.D degree in Computer Science from the University of Port Harcourt, Nigeria. He is a Lecturer I in the department of Computer Science, University of Uyo, Nigeria. His special fields of interest include mobile computing, wireless communications and computer networks as well as web technology. He is an associate member and member of Nigeria Computer Society and Computer Professionals Registration Council of Nigeria,

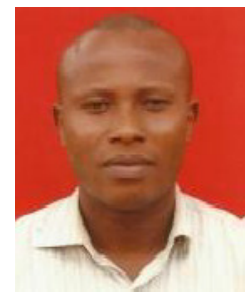
respectively. 